\title{
Evaluation of Delorme's Procedure in the Treatment of Complete Rectal Prolapse- A Comparison with Abdominal Rectopexy (Well's procedure)
}

\author{
Md. Ariful Alam Suman, ${ }^{1}$ Md. Habibullah Sarkar, ${ }^{2}$ Istiak Ahmed, ${ }^{3}$ Sulatanul Abedin, ${ }^{4}$ \\ Md. Shohidul Islam, ${ }^{5}$ Syeda Nafisa Islam ${ }^{6}$
}

\begin{abstract}
Background: There are versatile operative techniques for treating complete rectal prolapse. Every procedure has some advantages and disadvantages. Delorme's procedure and abdominal rectopexy (Well's procedure) have gained more popularity. But to determine which approach is better, it is needed to evaluate the functional outcome of both procedures.
\end{abstract}

Objective: To compare the outcome of Delorme's procedure and abdominal rectopexy to treat complete rectal prolapse.

Methodology: A randomized control trial was conducted in 25 patients with complete rectal prolapse in the department of Surgery, RMCH. They were divided into two groups by randomization. Fifteen patients included in Group-I underwent Delorme's procedure, and ten patients included in group-II underwent abdominal rectopexy (Well's procedure). The outcome of both procedures was compared postoperatively.

Results: In group-1, we have found uneventful outcomes of $10(66.66 \%)$ patients, and hemorrhage, minor incontinence, and retention of urine were found in $2(13.3 \%), 1(6.66)$, and 4(26.66\%) patients, respectively. In group-2 patients, $5(50 \%)$ patients recovered uneventfully, whereas hemorrhage, surgical site infection, retention of urine, bladder dysfunction, and constipation were found in $2(20 \%), 1(10 \%), 1(10 \%), 1(10 \%)$ and $2(20 \%)$ patients respectively. The mean operation time in group-I was $\mathbf{9 2 . 8 6}$ min and in Group 2 was 124.00 min with a p-value of 0.001 . The average post-operative hospital stay after Delorme's procedure was $<4$ days in 4 patients and 4-6 days in the rest 11 patients. But the hospital stay is a little lengthier in the case of abdominal rectopexy (Well's procedure), where seven patients were discharged within 4-6 days, and three patients were discharged after the 5th day of operation. In group I, expenditure was <7000 taka in $10(66.66 \%)$ patients, whereas in group-2, the cost was $10000-15000$ in $7(70 \%)$ patients with a p-value of 0.001 .

Conclusion: We can conclude that Delorme's procedure is comparatively safer and costeffective than Well's procedure, considering different vital parameters.

TAJ 2021; 34: No-1: 40-46

\section{Introduction}

Rectal prolapse describes a condition in which the entire layer of the rectal wall protrudes through the anal canal. It is classified into two types: complete or full-thickness and incomplete or partial

\footnotetext{
${ }^{1}$ Assistant Professor, Department of Colorectal Surgery, Rajshahi Medical College.

2 Professor of Surgery \& Vice-Principal, Rajshahi Medical College.

${ }^{3}$ Registrar, Department of Surgery, Rajshahi Medical College Hospital.

${ }^{4}$ Assistant Professor, Department of Surgery, Rajshahi Medical College.

${ }^{5}$ Assistant Professor, Department of Surgery, Rajshahi Medical College.

${ }^{6}$ Registrar, Department of Pediatrics, Rajshahi Medical College Hospital.
} 
thickness. Complete prolapse represents a protrusion of the entire layer of the rectum to the outside the anus and, thus, shows concentric folds. Incomplete prolapse is defined as a condition in which the protruding rectal wall is limited to the inside of the anal canal, which is also referred to as occult rectal prolapse or internal rectal intussusception1. In clinical practice, mucosal prolapse is readily confused with rectal prolapse. Mucosal prolapse is not a protrusion of the whole layer of the rectal wall but a portion of the rectal wall or only the anal mucosa. ${ }^{1}$

There is a peak in the incidence of this disease in the seventh decade of life. A total of $80 \%$ to $95 \%$ of the patients are elderly women. ${ }^{2,3}$ Though rectal prolapse was first described by Ebers Papyrus in $1500 \mathrm{BC}$, the etio-pathogenesis remains an enigma. ${ }^{4}$ Proposed etiologies include pregnancy, perineal nerve injury, chronic constipation, straining, neurologic and psychiatric disorders, and other conditions resulting in increased intra-abdominal pressure. ${ }^{5,6}$

More than 100 surgical procedures were described in literature as a treatment of rectal prolapse. These procedures can be categorized into abdominal and perineal procedures. ${ }^{7}$

Prerequisites for the development of rectal prolapse are (1) the presence of an abnormally deep pouch of Douglas (2) the lax and atonic condition of the muscles of the pelvic floor and anal canal, (3) weakness of both internal and external sphincters, often with evidence of pudendal nerve neuropathy and (4) the lack of normal fixation of the rectum, with a mobile mesorectum and lax lateral ligaments. With this abnormality, the small intestine, which lies against the anterior wall of the rectum, may force the rectum out through the anal canal. ${ }^{8,9,10}$

The aims of the operation are to correct the rectal prolapse, to restore normal bowel function, and to avoid a recurrence of full-thickness rectal prolapse. For many patients, constipation and fecal incontinence improve after surgery. ${ }^{11,12,13}$
Actually, two different surgical approaches can be distinguished: perineal and transabdominal procedures. In general, perineal surgical repairs supposedly cause less morbidity and mortality compared with abdominal operations. ${ }^{14,15}$ They are considered especially indicated in the elderly and/or high-risk patients as they can also be done in spinal or epidural anesthesia. ${ }^{14,16,17}$ On the other hand, recurrences seem more frequent after perineal techniques than after abdominal operations. $^{2,3,10}$

Delorme's procedure is a perineal technique for the repair of full-thickness rectal prolapse, first described by the French military surgeon Edmond Delorme in $1900 .^{18}$

The operation was initially seen to be technically simple and safe. However, it fell into disfavor after anecdotal reports of high recurrence rates and high post-operative morbidity and mortality rates. ${ }^{19}$

The popularity of Delorme's procedure reemerged in the past 20 years. Improved techniques have made it a relatively safe procedure that is ideal for those not fit enough to withstand an abdominal operation. Recent reports of Delorme's procedure still reports high recurrence rates. ${ }^{16,17}$ Although in contrast to certain abdominal rectopexy, it is not associated with significant post-operative constipation. The simplicity of approach and lack of major complications have made it popular with both surgeons and patients and led to its use as repeat as well as primary operations for rectal prolapse.

Abdominal repairs involve fixing the rectum to the sacrum by using either mesh or sutures. In addition to rectopexy, a sigmoid resection is commonly performed. The perineal approach is a conservative procedure to resect or remove the herniated area in patients with high operative risk. On the other hand, the abdominal approach is a more aggressive and radical procedure through laparotomy or laparoscopy.

The abdominal procedure mainly involves extensive bowel dissection and fixation; thus, the 
type of surgical procedure is classified according to the method or the location of bowel fixation. The representative abdominal procedures are suture rectopexy, anterior sling rectopexy (Ripstein operation), Posterior prosthetic rectopexy, resection and fixation. There are many complications that can be observed in different rectopexy like fibrosis and adhesion in suture rectopexy, hemorrhage and hematoma from pelvic venous plexus injury and stricture as long term post-operative complications observed in Ripstein procedure, recurrence, pelvic sepsis etc can be seen in the posterior prosthetic rectopexy.

It seems reasonable that patients who are fit for surgery without comorbidity should be offered abdominal rectopexy, as it is now associated with very low mortality rates. The abdominal operation with the lowest recurrence rate should be offered to the medically fit patient. Even though abdominal operations have higher morbidity, the fit patient is presumably capable of withstanding complications and should be given the best chance to cure the prolapse. ${ }^{20}$

So, as the surgical treatment of complete rectal prolapse, many pieces of literature supported both Delorme and abdominal rectopexy in a different situation and also from the perspective of fitness of the patients as well as different complications, interestingly, there is still dispute among surgeon to surgeon and center to center regarding the better choice of surgery as the treatment of procidentia.

In this study, it was tried to evaluate the outcome of Delorme's procedure in relation to general and local complications, patients satisfaction, improvement of bowel function, reduced hospital stay, reduced rate of recurrences and costeffectiveness in comparison to abdominal rectopexy.

\section{Materials and methods:}

It was a clinical trial done in the Department of Surgery, RMCH, from January 2016 to December 2018.
Inclusion Criteria

- Patients age 15 to 80 yrs

- Patients of both genders.

- All patients with complete rectal prolapse who underwent Delorme's procedure and abdominal rectopexy (Well's procedure) operation.

Exclusion Criteria

- Patient's age $>80$ yrs.

- Patients with severe comorbid disease unfit for anesthesia.

\section{Results}

This study was conducted among the indoor patients of Surgery wards of Rajshahi Medical College Hospital, Rajshahi, to evaluate two specific modes of treatment.

Due to the unavailability of cases, we had to set our sample size to 25 . Among them, 15 cases were set for group I (Delorme procedure), and the rest ten were set for group 2 (Abdominal rectopexy /Well's procedure). All cases of Group-2 were done through a laparoscopic approach.

Here the abdominal rectopexy technique has been set as the control. As the Delorme technique for complete rectal prolapse treatment is comparatively less practiced one and expertise matters, the technique is not very much popular in Bangladesh still yet. So our main aim is to test the hypothesis, "is Delorme procedure is better than the abdominal rectopexy in the treatment of complete rectal prolapse?" By testing the hypothesis, we can choose the effective procedure by the results of significance ( $p$-value $<0.05$ ) for our future guideline and protocol of treatment in this arena. 

Table I. Showing Distribution of Study Population According to Duration of Operation in Two Groups $(\mathbf{n}=25)$

\section{Group}

$\begin{array}{llll}\begin{array}{l}\text { Duration of Operation } \\ \text { (minutes) }\end{array} & \begin{array}{l}\text { Group-I } \\ \text { (Delorme) } \\ \mathbf{n = 1 5}\end{array} & \begin{array}{l}\text { Group 2 } \\ \text { (Abd. Rectopexy) }\end{array} & \text { p value } \\ & 5 & \mathbf{n = 1 0} & \\ 60-90 & 9 & 2 \\ >90-120 & 1 & 7 \\ >120 & \mathbf{1 5} & \mathbf{1 0} & <0.05 \\ \text { Total } & 92.86(11.63) & 124.00(13.90)\end{array}$

Table II: Showing Distribution of Study Population According to Outcome of Operation in Two Groups (n=25)

\begin{tabular}{|c|c|c|c|c|}
\hline \multirow{3}{*}{$\begin{array}{l}\text { Outcome of } \\
\text { Operation }\end{array}$} & \multicolumn{4}{|l|}{ Group } \\
\hline & $\begin{array}{l}\text { Group-I } \\
\text { (Delorme) }\end{array}$ & $\begin{array}{l}\text { Group } 2 \\
\text { (Abd. Rectopexy) }\end{array}$ & $x^{2}$ & $\mathbf{p}$ \\
\hline & $n=15$ & $\mathbf{n}=\mathbf{1 0}$ & & \\
\hline Uneventful & 10 & 5 & 9.375 & $<0.05$ \\
\hline Hemorrhage & 2 & 2 & 0.198 & $>0.05$ \\
\hline Wound infection & 0 & 1 & 1.563 & $>0.05$ \\
\hline $\begin{array}{l}\text { Retention of urine } \\
\text { (transient) }\end{array}$ & 4 & 1 & 1.042 & $>0.05$ \\
\hline Bladder dysfunction & 0 & 1 & 1.563 & $>0.05$ \\
\hline Bowel dysfunction & & & 3.788 & $>0.05$ \\
\hline Constipation & 0 & 2 & & \\
\hline Incontinence & 1 & 0 & & \\
\hline Sexual dysfunction & 0 & 0 & & \\
\hline Recurrence & 0 & 0 & & \\
\hline
\end{tabular}


Table III. Showing Distribution of Study Population According to Length of Postoperative Hospital Stays in Two Groups $(\mathbf{n}=25)$

$\begin{array}{llll}\begin{array}{l}\text { Length of Postoperative } \\ \text { Hospital Stay (days) }\end{array} & \begin{array}{l}\text { Group } \\ \text { Group-I } \\ \text { (Delorme) } \\ \mathbf{n = 1 5}\end{array} & \begin{array}{l}\text { Group 2 } \\ \text { (Abd. Rectopexy) }\end{array} & \mathbf{p} \\ \mathbf{n}=\mathbf{1 0} & \\ 44 & 4 & 0 & \\ 4-6 & 11 & 7 & <0.05 \\ >6 & 0 & 3 & \\ \text { Total } & \mathbf{1 5} & \mathbf{1 0} & \\ \text { Mean (SD) } & 4.4(1.4) & 6.0(1.6)\end{array}$

Table IV. Distribution of study population according to procedure cost in two groups

$\begin{array}{llll}\text { Procedure Cost (Taka) } & \begin{array}{l}\text { Group } \\ \text { Group-I }\end{array} & \begin{array}{l}\text { Group 2 } \\ \text { (Abd. Rectopexy) }\end{array} & \text { p value } \\ & \text { n=15 } & \mathbf{n = 1 0} & \\ <7000 & 10 & 0 & \\ 7000-9,999 & 5 & 3 & \\ 10,000-15,000 & 0 & 7 & <0.05 \\ \text { Total } & \mathbf{1 5} & \mathbf{1 0} & \\ \text { Mean }(\mathrm{SD}) & 6646(1518) & 10300(1888) & \end{array}$

\section{Discussion}

In this study, the maximum patients were found from the age group of $41-50$ years, followed by the nearest number of cases from $>50$ years.

Among the two groups, it was found that the mean age of the patients in Group I (Delorme procedure) is 37.40 years and in Group 2 (Well's procedure) is 46.60 years.

The presenting symptom common in all 25 patients was something coming down per rectum. The next common symptoms were incontinence, including mucus discharge, solid, and exclusive gas incontinence were in $12(48 \%)$ patients and associated co-morbidities in $9(36 \%)$ patients. There were $8(32 \%)$ patients who suffered from PR bleeding, and 6(24\%) patients suffered from constipation.
The mean operation time of Delorme procedure in group I patients was 92.86 minutes, whereas the mean operation time of abdominal rectopexy (Well's procedure) was 124.30 minutes.

Among the 15 patients of group I, we have found uneventful outcome of $10(66.66 \%)$ patients and hemorrhage, minor incontinence, and retention of urine were found in 2(13.3\%), 1(6.66), and $4(26.66 \%)$ patients as post-operative complications. No recurrence was found after Delorme procedure.

In the many recognized center of the world, it was found that recurrence is one of the commonest complications of Delorme procedure. But in our center, there was no recurrence.

Traditionally, the recurrence rate was the most critical factor in determining the effectiveness of the procedure. It was believed that the recurrence 
rate was high in patients undergoing Delorme's procedure. However, recent trials have failed to demonstrate that one approach is superior to the other when the functional outcome, operational morbidities, and overall costs have been considered. $^{23,24}$

In group II patients who underwent abdominal rectopexy (Well's procedure), we observed that $5(50 \%)$ patients recovered with the uneventful outcome, whereas hemorrhage, surgical site infection, retention of urine (transient), bladder dysfunction, and constipation were found in $2(20 \%), 1(10 \%), 1(10 \%), 1(10 \%)$ and $2(20 \%)$ patients respectively. So through these results, it can be assumed that abdominal rectopexy (Well's procedure) is more associated with different types of morbidity rather than Delorme's procedure. Interestingly, here also no recurrence or sexual dysfunction was found.

But in the different international studies, we found that sexual dysfunction in both males and females are relatively common complications of abdominal rectopexy (Well's procedure) due to unintentional pelvic nerve injuries. ${ }^{21,22}$

The average post-operative hospital stay after Delorme's procedure in group I patients was <4 days in case of $4(26.7 \%)$ patients and 4-6 days in case of rest $11(73.3 \%)$ patients. But the hospital stay is a little lengthier in case of abdominal rectopexy (Well's procedure) in group II patients. In that case, seven (70\%) patients were discharged within 4-6 days, and 3 (30\%) patients were discharged after the 6th day of operation.

The cost of the operations was significantly lower in the patients treated with Delorme's procedure than the abdominal rectopexy (Well's procedure).

\section{Limitations}

- Too small sample size, which was only 25.

- It is a single-center study; so it does not proclaim the scenario of other centers of Dhaka and the rest of the country. So we cannot get the total situation of the country.

- Bias of the surgeon may influence the result as it is only a single-blinded study.

\section{Conclusion}

Finding out the most appropriate surgical procedure in the treatment of complete rectal prolapse is a matter of controversy. Our results indicate that Delorme's procedure is a very effective procedure for complete rectal prolapse as it shows a significantly better functional outcome. Nevertheless, morbidity still is a factor of consideration. With the minor complications of Delorme's procedure and its acceptable recurrence rate and good functional results, we believe that this procedure should be considered the first choice for all patients, particularly young adults, presenting with complete rectal prolapse. Interestingly, we can recommend it strongly as we have found no recurrence in our study. Different types of morbidities are still the outcome factors in abdominal rectopexy (Well's procedure). But Delorme's procedure has some better advantages like shorter operation time, minimum costs, and obviously post-operative shorter hospital stay with early return to work and less serious complications with more uneventful outcomes. As a result, it may be a better choice to treat complete rectal prolapse than the abdominal rectopexy (Well's procedure).

\section{Recommendations}

- Furthermore, larger randomized studies with a long duration of follow-up are required to get conclusive evidence.

- The study should be multi-centered, doubleblinded to declare a procedure better than another and implement it in a national perspective.

\section{References}

1. Eung Jin Shin. Surgical Treatment of Rectal Prolapse. J Korean socie coloproctol2011; 27(1): 512.

2. Ashari LH, Lumley JW, Stevenson AR, Stitz RW. Laparoscopically-assisted resection rectopexy for rectal prolapse: ten years' experience. Dis Colon Rectum 2005; 48: 982-987.

3. Watts AM, Thompson MR. Evaluation of Delorme's procedure as a treatment for full-thickness rectal prolapse. Br J Surg 2000; 87:218-222. 
4. Ballantyne $\mathrm{GH}$. The historical evolution of anatomic concepts of rectal prolapse. Semin Colon Rectal Surg $1991 ; 2: 170-9$.

5. Madoff RD, Mellgren A. One hundred years of rectal prolapse surgery. Dis Colon Rectum 1999; 42:441-50.

6. Marceau C, Parc Y, Debroux E, Tret E, Parc R. Complete rectal prolapse in young patients: psychiatric disease a risk factor of poor outcome. Colorectal Dis 2005; 7:360-5.

7. Uhlig BE, Sullivan ES. The modified Delorme operation: its place in surgical treatment for massive rectal prolapse. Dis Colon Rectum 1979 ; 22:513-21.

8. Roig JV, Buch E, Alós R, et al. Anorectal function in patients with complete rectal prolapse: differences between continent and incontinent individuals. Rev Esp Enferm Dig 1998; 90:794-805.

9. Kuijpers HC. Treatment of complete rectal prolapse: to narrow, to wrap, to suspend, to fix, to encircle, to plicate or to resect? World J Surg 1992; 16:826-830.

10. Nicholls RJ. Rectal prolapse and the solitary ulcer syndrome. Ann Ital Chir 1994, 65:157-162

11. Kellokumpu $\mathrm{IH}$, Vironen $J$, Scheinin $T$. Laparoscopic repair of rectal prolapse: a prospective study evaluating surgical outcome and changes in symptoms and bowel function. Surg Endosc 2000; 14:634-640.

12. Kariv $\mathrm{Y}$, Delaney CP, Casillas S, Hammel J, Nocero $J$, Bast $J$ et al. Long-term outcome after laparoscopic and open surgery for rectal prolapse: a case-control study. Surg Endosc 2006; 20:35-42.

13. Tsunoda A, Yasuda N, Yokoyama N, Kamiyama G, Kusano M. Delorme's procedure for rectal prolapse: clinical and physiological analysis. Dis Colon Rectum 2003; 46:1260-1265.

14. Oliver GC, Vachon D, Eisenstat TE, Rubin RJ, Salvati E. Delorme's procedure for complete rectal prolapse in severely debilitated patients. An analysis of 41 cases. Dis Colon Rectum 1994; $37: 461-467$.
15. Jorge JM, Wexner SD. Etiology and management of fecal incontinence. Dis Colon Rectum 1993; 36:77-97.

16. Tobin SA, Scott IHK. Delorme operation for rectal prolapse. Br J Surg 1994; 81: 1681-4.

17. Watkins BP, Landercasper J, Belzer GE, Rechner $P$, Knudson R, Bintz M, Lambert P. Long-term follow-up of the modified Delorme procedure for rectal prolapse. Arch Surg 2003;138:498-502.

18. Delorme E. Sur le traitment des prolapsus du rectum totaux, par l' excision de la muqueuse rectal ou recto-colique. Bulletin et Memories de la Societe de Chirrurgie de paris 1900; 26: 498-9.

19. Girsch LJ. In: Moskalenko VW. Modification of Delorme's resection of rectal mucosa for prolapse of the rectum. Int J Surg 1973; 58: 192-4.

20. Mann CV, Hoffman C. Complete rectal prolapse the anatomical and functional results of the treatment by an extended abdominal rectopexy. $\mathrm{Br} \mathrm{J}$ Surg 1988; 75: 34-37.

21. Mohammad SF, Ali RK, Amir K, Mohammad R.K. Department of Surgery, Imam Khomeini Medical Center, Tehran University of Medical Sciences, Tehran, Iran Delorme's Procedure: An Effective Treatment for a Full-Thickness Rectal Prolapse in Young Patients. Ann Coloproctol 2013;29(2):60-65

22. Hemanth Makineni, Poornachandra Thejeswi, B.K. Shivprasad Rai; Evaluation of Clinical Outcomes after Abdominal Rectopexy and Delorme's Procedure for Rectal Prolapse: A Prospective Study. Journal of Clinical and Diagnostic Research 2014; 8(5): 4-6

23. Tou S, Brown SR, Malik AI, Nelson RL. Surgery for complete rectal prolapse in adults. Cochrane Database of Systematic Reviews 2008.; 4: Art. No.: CD001758

24. Senapati A, Gray RG, Middleton LJ, Harding J, Hills RK, Armitage NC,et al. Randomised comparison of surgical treatments for rectal prolapse. PROSPER Collaborative Group Colorectal Dis 2013. A;15(7):858-68.

25. Lieberth M, Kondylis LA, Reilly JC, Kondylis PD. The Delorme repair for full-thickness rectal prolapse: a retrospective review. Am J Surg 2009; 197:418-23. 